\title{
STUDY OF THE MORPHOLOGICAL STRUCTURE OF ENAMEL AND CORRELATION OF ITS CHEMICAL COMPOSITION WITH DENTIN IN INTACT TEETH AND WITH A CERVICAL PATHOLOGY
}

\author{
Iryna Zabolotna \\ Department of Dentistry №2, Donetsk National Medical University, Liman, Ukraine
}

\begin{abstract}
INTRODUCTION: The increase in the intensity of caries and non-carious lesions of the teeth leads to significant disorders in the dentoalveolar apparatus manifested themselves not only as aesthetic but also as functional disorders in the absence of timely adequate treatment.

Овјестіves: The increase in the prevalence and intensity of cervical lesions of hard dental tissues is the cause of aesthetic and functional disorders in the dentoalveolar apparatus. To study the morphological structure of enamel, its features depending on the presence and type of cervical pathology; to determine correlations of the chemical composition of enamel and dentin in intact teeth and with cervical pathology.

MATERIAL AND METHODS: There were examined 29 clinically extracted teeth of both jaws and their longitudinal sections using a JSM-6490 LV focused beam electron microscope with system of energy-dispersive X-ray microanalysis. The chemical composition of 290 enamel areas and 235 dentine areas in the incisal region (tubercle), equator, cervical area.

RESULTS: The correlation between enamel and dentin has been determined: inverse - based on the content of $\mathrm{P}$ and $\mathrm{C}, \mathrm{Ca}$ and $\mathrm{O}$ (in all anatomical areas), $\mathrm{Mg}$ and $\mathrm{Ca}, \mathrm{Mg}$ and $\mathrm{P}$ (in the incisal region (tubercle), equator); direct - based on the content of $\mathrm{Mg}$ and $\mathrm{Ca}, \mathrm{Mg}$ and $\mathrm{P}$ (cervical area). The exception was the correlation between $\mathrm{Mg}$ and $\mathrm{Ca}$ in the incisal region (tubercle) in the group of the teeth with cervical pathology ( $r=0.363), \mathrm{Ca}$ and $\mathrm{O}$ in the cervical area in the group of the teeth with cervical caries and clinically intact hard tissues $(r=0.620)$.

Conclusions: The revealed features in the morphological structure and chemical composition of enamel, the presence of the correlations with dentin will allow to understand the mechanism of the development of cervical pathology deeper and substantiate the principles of its treatment and prevention.
\end{abstract}

KEY WORDS: dental caries, enamel, dentine, scanning electron microscope, non-carious cervical lesions.

J Stoma 2021; 74, 1: 9-15

DOI: https://doi.org/10.5114/jos.2021.104691

\section{INTRODUCTION}

The increase in the intensity of caries and non-carious lesions of the teeth leads to significant disorders in the dentoalveolar apparatus manifested themselves not only as aesthetic but also as functional disorders in the absence of timely adequate treatment [1-3]. The features of the morphological structure and chemical composition of hard dental tissues reflect complex processes associated with age-related and pathological conditions

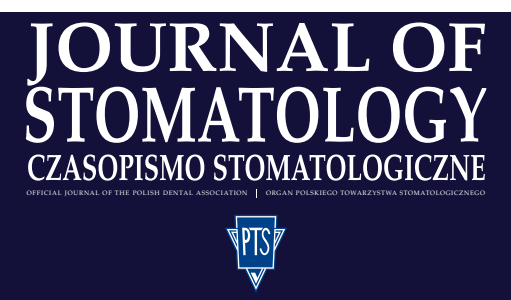

AdDress For Correspondence: Dr. Iryna Zabolotna, Dental Department №2, Donetsk National Medical University, Bulvar Mashinobydivelnikiv 39a, building 6, room 6103, Kramatorsk, 84313, Ukraine, e-mail: myhelp200@gmail.com

ReCEIVED: 06.01.2021 • ACCEPTED: 28.02.2021 • PUBLISHED: 30.03.2021 
in the body and they determine their development $[1,4]$. Mineralization of enamel and dentin is mainly determined by the content of calcium and phosphorus in them, the amount of which is heterogeneous in different areas of the teeth and it significantly differs from the type of pathology $[4,5]$. The strength of dental tissues is influenced not only by the optimal ratio of the main macroelements but it's also influenced by the imbalance of microelements $[5,6]$.

There is a constant exchange of mineral ions in enamel which come from saliva through the pores and they are adsorbed on its surface [5, 7]. Another source of the ions in enamel is from cementum through the cemento-dentin junction to the enamel-dentin junction [5]. The level of permeability of hard dental tissues is very high and the surface layer of enamel absorbs the greatest amount of the substances [5]. The most soluble enam$\mathrm{el}$ is in the cervical area and the proximal contact surface of the tooth where its thickness is minimal that indicates reduced mineralization and predisposition to the development of a carious process [5]. The cervical form of dental caries is diagnosed in a significant part of the clinical cases in the age group 30-50 years [8]. The process of demineralization is more pronounced in dentin than in enamel due to the faster penetration and spread of microorganisms along the dentinal tubules [9]. The areas of demineralization were revealed in $69 \%$ of the cases in dentin of the teeth with a wedge-shaped defect [10]. The prevalence of a wedge-shaped defect increases with age $[3,11,12]$ and it reaches its maximum by the age of $50-70$ [8].

The identification of distinctive features in the morphological structure of enamel and dentin and the correlation of their chemical composition in clinically intact teeth and teeth with cervical pathology will allow to understand the mechanisms of their occurrence and development deeper, evolve the tactics of the prevention and treatment.

\section{OBJECTIVES}

To study the morphological structure of enamel, its features depending on the presence and type of cervical pathology; to determine possible correlations of the chemical composition of enamel and dentin in clinically intact teeth, teeth with cervical caries and a wedgeshaped defect.

\section{MATERIAL AND METHODS}

We examined 29 clinically extracted teeth of both jaws and their longitudinal sections (12 clinically intact ones, 10 with wedge-shaped defects, 7 with cervical caries) of the patients aged 25-54 years using a JSM-6490 LV focused beam electron microscope (scanning) with system of energy-dis persive X-ray microanalysis INCA
Penta FETx3 (OXFORD Instruments, England) according to the previously described method [13, 14]. The teeth were extracted for orthodontic indications. The morphological structure was studied using $\times 40$... $\times 4000$ magnification [13]. We calculated local mass fractions of chemical elements using the picfon ratio method taking into account the corrections for atomic number, fluorescence and absorption, measured in normal mass percentage (normal mass \%). The mineral composition of 290 enamel areas and 235 dentine areas in the incisal region (tubercle) (IR), equator (E), cervical area (CA) has been determined as a percentage of the weight amounts of carbon, oxygen, calcium, phosphorus, sodium, magnesium, sulfur, chlorine, zinc, potassium, and aluminum. Replication measurements were averaged in one sample before statistical analysis. To identify possible relationships between the chemical composition of enamel and dentin the correlation was determined in the following groups: I - teeth with a wedge-shaped defect and clinically intact hard tissues, II - teeth with cervical caries and clinically intact hard tissues, III -teeth with cervical pathology. The study was conducted at the base of Donetsk Institute of Physics and Technology of the National Academy of Sciences of Ukraine. The work was performed in accordance with the principles of the Helsinki Declaration of the World Medical Association "Ethical Principles of Medical Research with the Involvement of a Human being as a Research Object", Order No. 690 of the Ministry of Health of Ukraine (dated September 23, 2009) and approved by the Bioethics Commission of the Donetsk national medical university. Prior to engaging in the study, all the participants were provided with a written informed consent.

\section{STATISTICAL ANALYSIS}

Statistical analysis was performed using the Statistica 12.0 computer program (3BA94C4ED07A). To check the presence of the relationship between the variables, the correlation analysis was carried out (Pearson's parametric correlation method) based on the determination of the parametric Brave-Pearson coefficient $(r)$ with the confidence level of $95 \%$. The reliability of obtained results was assessed using Student's $t$-test, the correlation between the indicators - based on Student's $t$-test using $Z$-test (Fisher's $Z$-test). The differences were considered statistically significant at $p \leq 0.05$. The significance of the differences between the groups was assessed basing on the analysis of variance.

\section{RESULTS}

Electron microscopic examination of the surface enamel of clinically intact teeth revealed its oriented structure where its main formation is arcade-shaped prisms that are tightly adjacent to each other, their aver- 


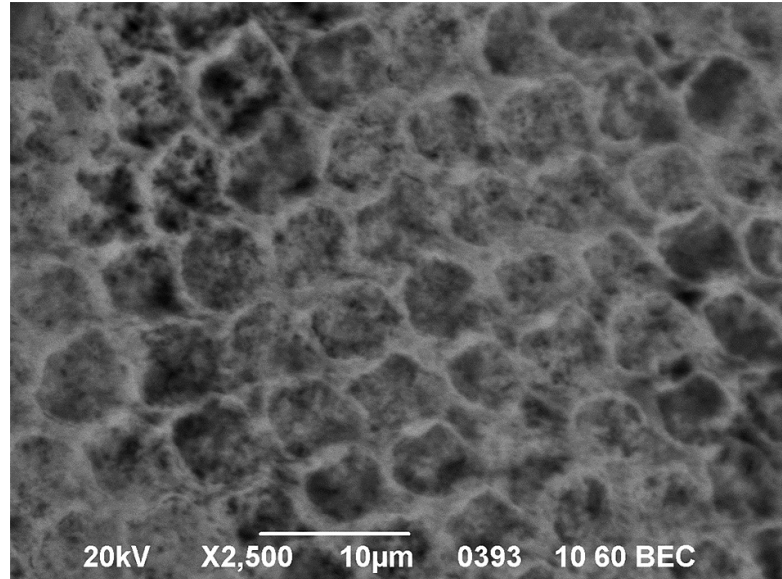

FIGURE 1. Electron microscopic image of the enamel (cervical area) of 3.5 clinically intact tooth $(\times 2500)$

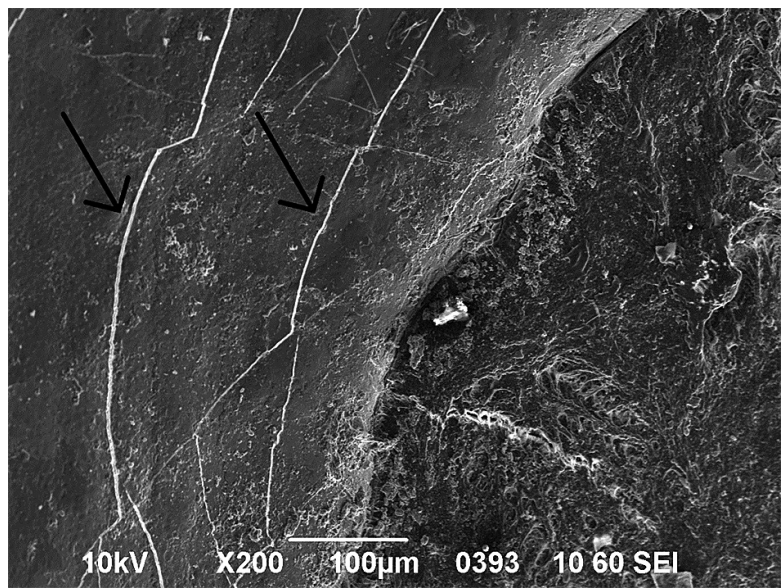

FIGURE 3. Electron microscopic image of the enamel (cervical area) of 3.7 clinically intact tooth $(\times 200)$. Horizontal cracks (arrowed)

age diameter was $5.33 \pm 0.22 \mu \mathrm{m}$ (Figure 1 ). The vestibular surface of enamel had an even smoothed appearance; the traces from multidirectional scratches and cracks were visualized on it [13]. The high prevalence (90.2-99.4\%) and opening width $(0.05-42.12 \mu \mathrm{m})$ of enamel cracks were determined as well as the features of their direction were revealed [13-15]. We identified the cracks which were perpendicular to the cemento-enamel junction more often - in $90.5 \%$ of the cases (Figure 2), in combination with parallel (Figure 3 ) and oblique directions - in $6.3 \%$ and $3.2 \%$ of the cases, respectively $[13,15]$. A large number of cracks were diagnosed in CA of the vestibular surface of the teeth -3.21 per $1 \mathrm{~mm}^{2}$, less in IR -0.75 per $1 \mathrm{~mm}^{2}(\times 300)$ [13]. Using x1500-4000 magnification it was determined that they were localized in the interprismal space which had a lower strength [13, 14]. Revealed depth of enamel in CA is the place where the enamel rods leave. A small number of "cratered" features were identified (Figure 4). In intact teeth there

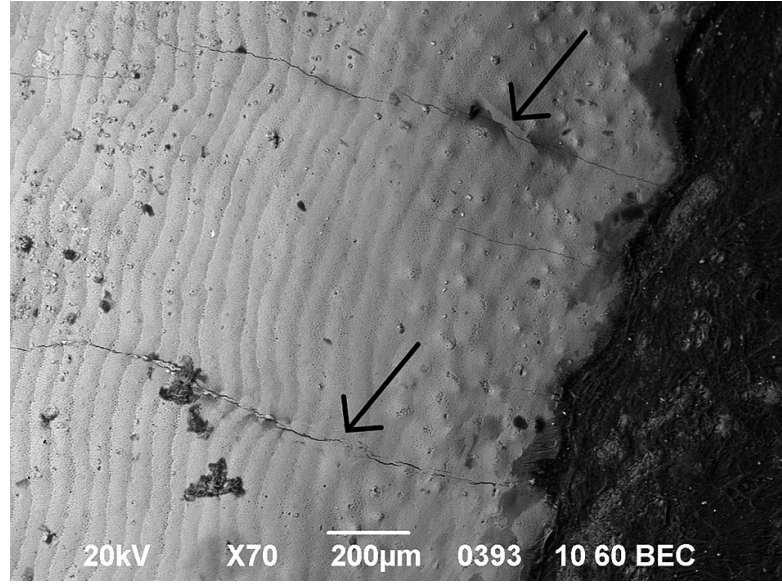

FIGURE 2. Electron microscopic image of the enamel (cervical area) of 4.6 clinically intact tooth $(\times 70)$. Vertical cracks (arrowed)

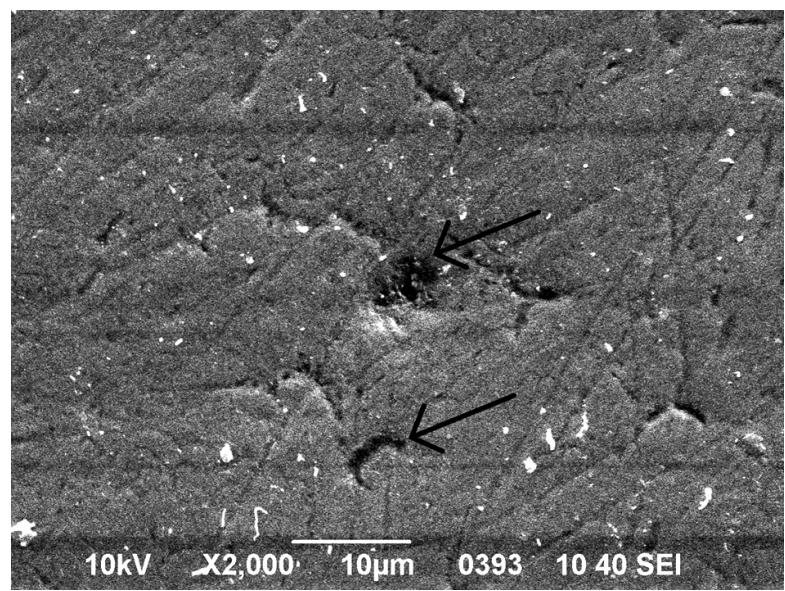

FIGURE 4. Electron microscopic image of the enamel (cervical area) of 1.1 clinically intact tooth $(\times 2000)$. The depth and 'cratered' features (arrowed)

was a pronounced cemento-enamel junction which was characterized by the overlap of enamel on cementum in $57.9 \%$ of the cases and the overlap of cementum on enamel - in $42.1 \%$ of the cases (Figure 5) [14]. Deeper cracks in enamel were determined in case of overlapping enamel on cementum (87.5\% of the cases). With $\times 1000$ and greater magnification the outlines of the perikymata (Retzius lines) were more clearly visualized in the form of uneven lines where leaving of arcade-shaped enamel rods was detected at the junctions (Figure 6).

The structure of the surface layer of enamel in the area of a wedge-shaped defect looked like open enamel rods with scalloped edges (Figure 7). The depth, opening width and the number of enamel cracks increased on the vestibular surface, especially in CA where they had a horizontal direction [13]. "Cratered" features were identified significantly more often than in clinically intact teeth. The cemento-enamel junction had an indistinct outline and it was characterized only by the overlap 


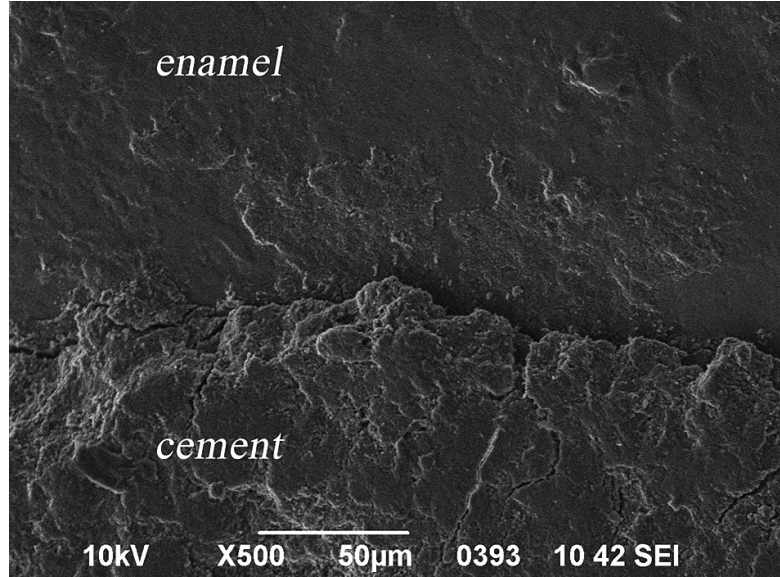

FIGURE 5. Electron microscopic image of the cementoenamel junction (cementum overlaps enamel) of $4.6 \mathrm{cli}$ nically intact tooth $(\times 500)$

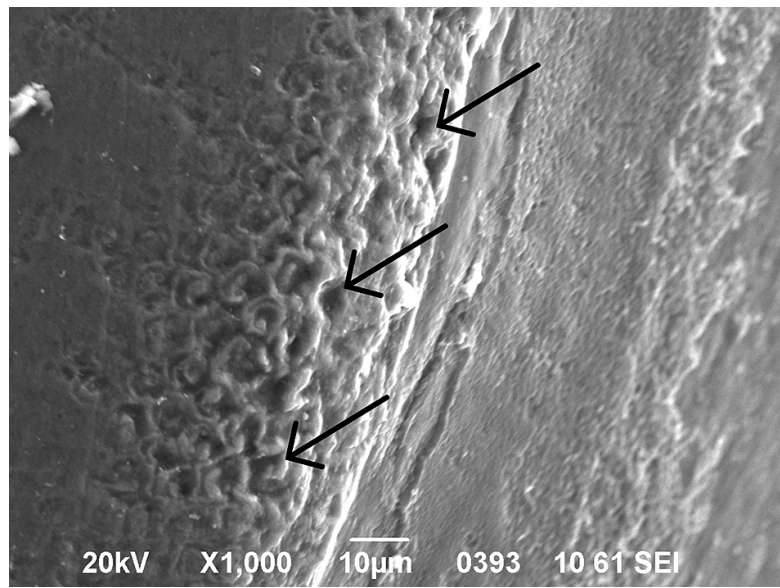

FIGURE 7. Electron microscopic image of the enamel (cervical area) of 1.5 with a wedge-shaped defect $(\times 1000)$. The open enamel rods (arrowed)

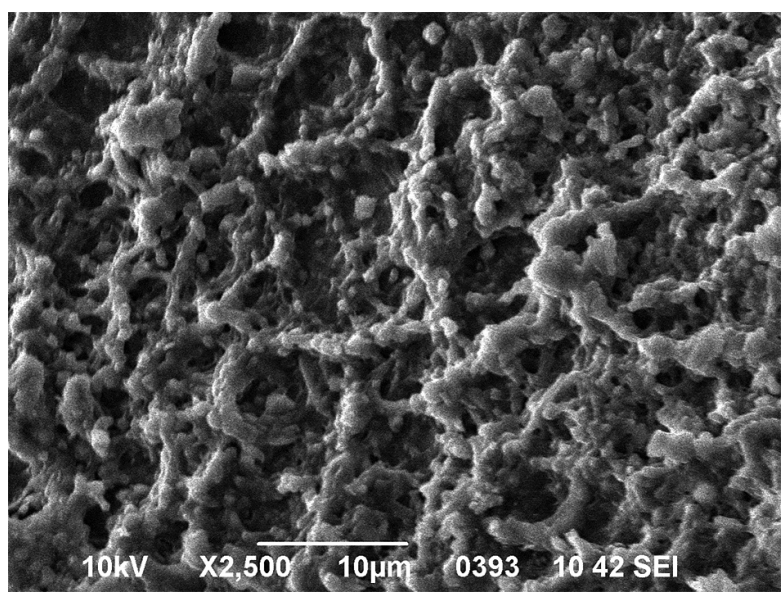

FIGURE 9. Electron microscopic image of the enamel (cervical area) of 3.3 with cervical caries $(\times 2500)$

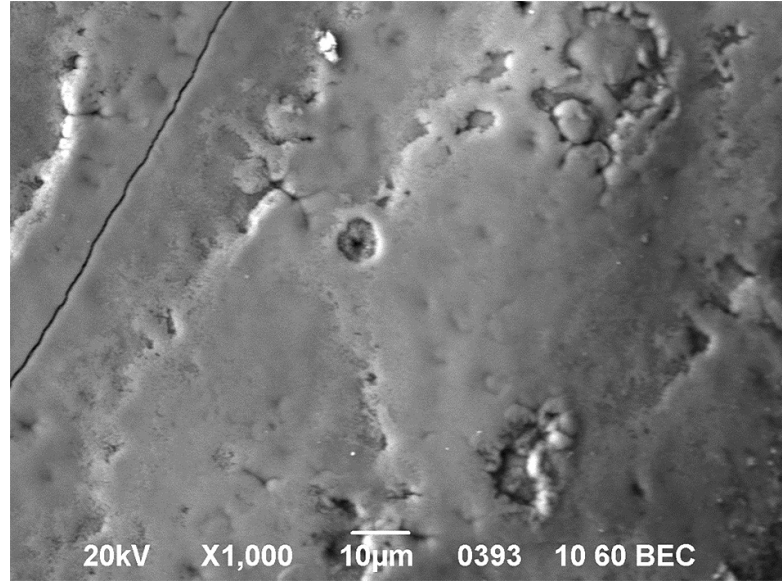

FIGURE 6. Electron microscopic image of the perikymata (cervical area) of 3.7 clinically intact tooth $(\times 1000)$

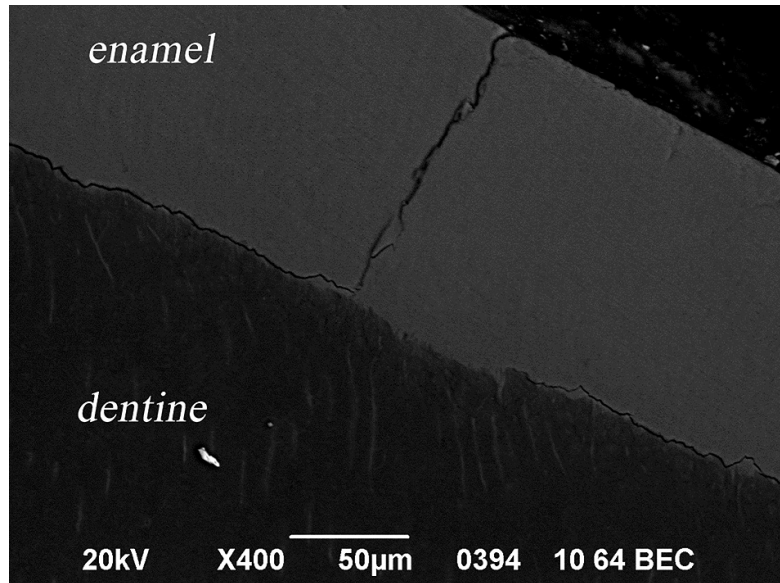

FIGURE 8. Electron microscopic image of the section of 2.4 with a wedge-shaped defect $(\times 400)$

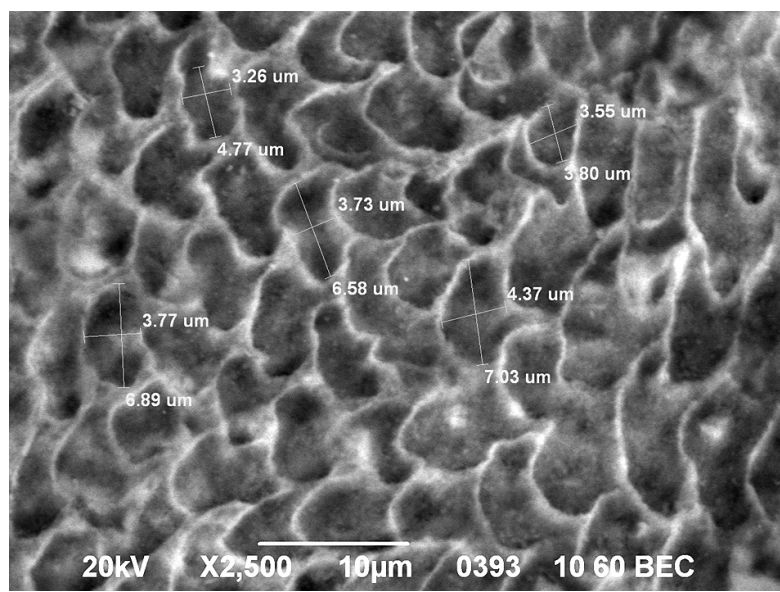

FIGURE 10. Electron microscopic image of the enamel incisal region of 1.1 with a wedge-shaped defect $(\times 2500)$ 
TABLE 1. The correlation between the chemical composition of enamel and dentin

\begin{tabular}{|c|c|c|c|c|c|c|c|}
\hline \multirow[t]{4}{*}{ Chemical element } & \multirow[t]{4}{*}{ Area } & \multicolumn{6}{|c|}{ Chemical element } \\
\hline & & \multicolumn{3}{|c|}{$P$} & \multicolumn{3}{|c|}{ Ca } \\
\hline & & \multicolumn{6}{|c|}{ Group } \\
\hline & & I & II & III & I & II & III \\
\hline \multirow[t]{3}{*}{ C } & $\mathbb{I R}$ & $\begin{array}{c}-0.642 \\
p<0.001\end{array}$ & $\begin{array}{c}-0.639 \\
p<0.001\end{array}$ & $\begin{array}{c}-0.690 \\
p<0.001\end{array}$ & - & $\begin{array}{c}-0.266 \\
p=0.001\end{array}$ & $\begin{array}{c}-0.132 \\
p=0.050\end{array}$ \\
\hline & $E$ & $\begin{array}{c}-0.721 \\
p<0.001\end{array}$ & $\begin{array}{c}-0.591 \\
p<0.001\end{array}$ & $\begin{array}{c}-0.700 \\
p<0.001\end{array}$ & $\begin{array}{c}-0.445 \\
p<0.001\end{array}$ & $\begin{array}{c}-0.361 \\
p<0.001\end{array}$ & $\begin{array}{c}-0.396 \\
p<0.001\end{array}$ \\
\hline & CA & $\begin{array}{c}-0.534 \\
p<0.001\end{array}$ & $\begin{array}{c}-0.863 \\
p<0.001\end{array}$ & $\begin{array}{c}-0.655 \\
p<0.001\end{array}$ & $\begin{array}{c}-0.588 \\
p<0.001\end{array}$ & $\begin{array}{c}-0.780 \\
p<0.001\end{array}$ & $\begin{array}{c}-0.485 \\
p<0.001\end{array}$ \\
\hline \multirow[t]{3}{*}{$\mathrm{Mg}$} & $\mathbb{R}$ & $\begin{array}{c}-0.243 \\
p=0.001\end{array}$ & $\begin{array}{c}-0.206 \\
p=0.009\end{array}$ & $\begin{array}{c}-0.179 \\
p=0.008\end{array}$ & $\begin{array}{c}-0.435 \\
p<0.001\end{array}$ & $\begin{array}{c}-0.293 \\
p<0.001\end{array}$ & $\begin{array}{c}0.363 \\
p<0.001\end{array}$ \\
\hline & $E$ & $\begin{array}{c}-0.707 \\
p<0.001\end{array}$ & $\begin{array}{c}-0.329 \\
p=0.001\end{array}$ & $\begin{array}{c}-0.324 \\
p<0.001\end{array}$ & $\begin{array}{c}-0.539 \\
p<0.001\end{array}$ & $\begin{array}{c}-0.468 \\
p<0.001\end{array}$ & $\begin{array}{c}-0.325 \\
p<0.001\end{array}$ \\
\hline & CA & $\begin{array}{c}0.360 \\
p=0.003\end{array}$ & $\begin{array}{c}0.539 \\
p=0.001\end{array}$ & $\begin{array}{c}0.495 \\
p<0.001\end{array}$ & $\begin{array}{c}0.270 \\
p=0.030\end{array}$ & $\begin{array}{c}0.481 \\
p=0.003\end{array}$ & $\begin{array}{c}0.325 \\
p=0.002\end{array}$ \\
\hline \multirow[t]{3}{*}{0} & $\mathbb{R}$ & $\begin{array}{c}0.359 \\
p=0.001\end{array}$ & $\begin{array}{c}0.213 \\
p=0.007\end{array}$ & $\begin{array}{c}0.227 \\
p=0.001\end{array}$ & $\begin{array}{c}-0.814 \\
p<0.001\end{array}$ & $\begin{array}{c}-0.548 \\
p<0.001\end{array}$ & $\begin{array}{c}-0.682 \\
p<0.001\end{array}$ \\
\hline & $E$ & - & - & $\begin{array}{c}0.203 \\
p=0.015\end{array}$ & $\begin{array}{c}-0.328 \\
p=0.001\end{array}$ & $\begin{array}{c}-0.294 \\
p=0.003\end{array}$ & $\begin{array}{c}-0.252 \\
p=0.003\end{array}$ \\
\hline & CA & $\begin{array}{c}-0.708 \\
p<0.001\end{array}$ & $\begin{array}{c}0.678 \\
p<0.001\end{array}$ & - & $\begin{array}{c}-0.761 \\
p<0.001\end{array}$ & $\begin{array}{c}0.620 \\
p<0.001\end{array}$ & $\begin{array}{c}-0.266 \\
p<0.001\end{array}$ \\
\hline
\end{tabular}

of enamel on cementum [14]. We identified the impairment of the relationship between dentine and enamel with the formation of microcracks at the enameldentin junction on the section (Figure 8). The examination of the enamel in the area of a carious process showed a change in the shape of the enamel rods: their thickening and loosening (Figure 9). The average diameter of the rods decreased to $4.78 \pm 0.47 \mu \mathrm{m}$ in the areas of enamel abrasion, but the differences were insignificant $(p=0.24)$ (Figure 10).

The results of determining the chemical composition of enamel in the area of IR, E, CA of clinically intact teeth and teeth with cervical pathology were published previously [16]. Inverse correlation was found between carbon and oxygen, carbon and phosphorus, oxygen and calcium, magnesium and potassium $(p \leq 0.05)$ in all studied areas [16]. The correlation of the chemical composition of enamel and dentin in IR had distinctive features for $\mathrm{Zn}$ and $\mathrm{Na}$ depending on the group of the samples. It was inverse $(r=-0.180)$ in group I (teeth with a wedge-shaped defect and clinically intact hard tissues), and there was direct correlation of moderate strength ( $r=0.676$ and $r=0.659$, respectively) in group II (teeth with cervical caries and clinically intact hard tissues) and group III (teeth with a cervical pathology), $p<0.05$. In the area of $\mathrm{E}$ there was inverse correlation of moderate strength $(r=-0.565)$ between $\mathrm{Cl}$ and $\mathrm{Na}$ in group II, and direct correlation of high strength
( $r=0.864$ and $r=0.841$, respectively) in groups I and III, $p<0.05$. The correlation between $\mathrm{Ca}$ and $\mathrm{O}$ had distinctive features in CA. There was direct correlation of moderate strength $(r=0.620)$ in group II, it was inverse ( $r=-0.761$ and $r=-0.266$, respectively) in groups I and III, $p<0.05$.

We identified the correlation between the chemical composition of enamel and dentin in all anatomical areas of the teeth: inverse - between $\mathrm{P}$ and $\mathrm{C}, \mathrm{P}$ and $\mathrm{Mg}$ (in the area of IR and E), Ca and O (in the area of IR and $\mathrm{E}$, in CA teeth of groups I and III), Ca and $\mathrm{Mg}$ (in the area of E, in IR of the teeth of groups I and II); direct - between $\mathrm{P}$ and $\mathrm{Mg}$ (in $\mathrm{CA}$ ), $\mathrm{Ca}$ and $\mathrm{O}$ (in $\mathrm{CA}$ of the teeth of group II), $\mathrm{Ca}$ and $\mathrm{Mg}$ (in CA, IR of the teeth of group III) (Table 1).

\section{DISCUSSION}

The results of electron microscopic examination of the vestibular surface of the enamel of intact specimens corresponded to the data of other authors $[1,5,9,17]$, and the mean value of the diameter of the enamel rods (5.33 $\pm 0.22 \mu \mathrm{m})$ was in the corresponding range: $4-6 \mu \mathrm{m}[1]$, 4.0-7.5 $\mu \mathrm{m}$ [5]. The heads of the enamel rods rise above the surface in the cervical and proximal regions, and "dimpled" features may be formed from the craters [5]. According to Michael et al. (2010), horizontal, vertical 
and uneven scratches can occur as a result of toothbrush movements. Perhaps the horizontal and vertical furrows are the result of prolonged unidirectional abrasion and erosion which leads to a combined effect [18]. Perikymata diagnosed in CA were not identified in other anatomical areas of tooth enamel of the people aged 25-54 years, since they are worn by the age of twenty and they can remain only in the cervical area [5].

The structure of enamel and dentin of teeth in noncarious and carious processes has significant differences [1]. When studying the enamel structure of the teeth with a wedge-shaped defect Chistyakova et al. (2017) also found open enamel rods on transverse sections and the formation of microcrevices at the enamel-dentin junction which was explained by demineralization of the surface layer of enamel due to the impairment of its structure [11]. According to other data, longitudinal sections revealed internal microcracks extending to the pulp chamber [19]. A number of researchers pay their attention to the difference in the location of the enamel rods in wedge-shaped defects, their positioning in particular, meanwhile it loses its clear location in the surface area and it mainly forms a conglomerate without a clear structure of the rods, the matter loss between prismatic spaces [1]. Small furrows identified by Walter et al. (2014) were parallel to the cemento-enamel junction and they were present in $11 \%$ of the teeth with wedge-shaped defects [20]. Horizontal furrows and microcracks were also found in the teeth with non-carious cervical lesions by other researchers, their presence was explained by mechanical forces such as toothbrush abrasion $[18,19]$. The presence of the furrows and surface defects in the teeth with wedge-shaped defects suggests a possible role for tensile stress due to occlusal loading $[18,19]$. The cracks identified by the researchers and the crater appearance of the enamel surface are likely the result of abfraction as a result of biomechanical disruption of the tooth structure [18]. It is abfraction that is considered the most likely cause of non-carious cervical lesions [21]. Structural changes in enamel can lead to a change in resistance to the action of erosive factors [18]. Susceptibility to non-carious lesions of the cervical area (erosion, abrasion and abfraction) is also associated with the structural features of the cemento-enamel junction [22]. Such variant of its structure as the overlap of cementum on enamel was determined in $42.1 \%$ of the cases [14], Asma Saher Ansari et al. (2019) detected it in $57.6 \%$ [22]. It was the most common structure of the cemento-enamel junction of molars and premolars (78.6\% and $82.8 \%$, respectively) [22].

The morphological structure of enamel of the teeth affected by caries has a number of features. Pavlova et al. (2014) found that the pores on the enamel surface have an irregular pattern, there are some microrelief changes even in the area of visually unchanged enamel as it becomes rough $[9,17]$. A carious process develops mainly along the edges of the enamel rods [5].
Increased occlusal stress on the teeth is diagnosed in the form of wear facets which were detected in $78 \%$ of examined patients with non-carious cervical lesions according to some data [23]. The detection of occlusal wear facets and micro-fractures on the teeth with wedge-shaped defects confirms occlusal stress as the main etiological factor and as the root cause of this form of pathology [23] in some cases. The presence of abrasion of hard dental tissues increases the likelihood of the appearance of deeper cracks on the vestibular surface of the enamel [15].

While studying the chemical composition of enamel [16] inverse correlation was detected between calcium and oxygen, phosphorus and carbon $(p \leq 0.05)$ as a result of the research. The exception was the samples of group II (with cervical caries and clinically intact hard tissues) where direct correlation between the content of calcium and oxygen was determined in CA $(r=0.620), p \leq 0.001$. Other authors have identified a sharp increase in the oxygen content in both enamel and dentin in the case of a carious process. These processes can be considered as a result of the vital activity of bacteria [9]. We determined the correlation between the chemical composition of enamel and dentin in the content of magnesium and calcium, magnesium and phosphorus in all studied anatomical areas of the samples. But the nature of the relationship draws attention to itself: it is inverse in the area of IR and the equator and it is direct in CA. The exception was the correlation between magnesium and calcium in IR region in group III (the samples with cervical pathology) where it was direct $(r=0.363)(p \leq 0.001)$. The magnesium content decreases with increasing calcium content [24].

A number of researchers pay their attention not only to phosphorus and calcium but also to the special role of sodium when the change in its amount is associated with the changes in the structure of hard dental tissues [4]. Taking into account that the ionic radius of sodium cation is less than the ionic radii of potassium and calcium cations, and the mobility of sodium ion is greater than the mobility of the mentioned cations, the authors have suggested that sodium cations penetrate into hydroxyapatite crystal lattice displacing potassium and calcium cations [25]. We determined inverse correlation between sodium and calcium in all studied anatomical zones, between sodium and phosphorus - at E; direct correlation between sodium and chlorine - in CA where the pathology of hard dental tissues was diagnosed.

\section{CONCLUSIONS}

Deep cracks in enamel can be considered to be a condition preceding the appearance of wedge-shaped teeth defects in case of predisposing factors. The chemical composition of enamel and dentin reflects the processes associated with pathological conditions in hard dental tissues. Revealed patterns of these processes, the presence of correlation will allow to understand the mechanism of 
the development of cervical lesions deeper and substantiate the principles of the treatment and prevention.

\section{CONFLICT OF INTEREST}

The authors declare no potential conflicts of interest with respect to the research, authorship, and/or publication of this article.

\section{References}

1. Tkachenko IM, Brailko NN, Kovalenko VV, Nazarenko ZJ, Sheshukova OV. Morphological study of enamel and dentin teeth with carious process and non-carous lesions. Wiad Lek 2018; 71: 1002-1005 [In Russian].

2. Zuza A, Racic M, Ivkovic N, et al. Prevalence of non-carious cervical lesions among the general population of the Republic of Srpska, Bosnia and Herzegovina. Int Dent J 2019; 69: 281-288.

3. Teixeira DNR, Zeola LF, Machado AC, et al. Relationship between noncarious cervical lesions, cervical dentin hypersensitivity, gingival recession, and associated risk factors: a cross-sectional study. J Dent 2018; 76: 93-97.

4. Tkachenko IM, Kovalenko VV. Research of microelement composition of enamel and dentine of teeth at caries and increased tooth erosion. Bulletin of Problems in Biology and Medicine 2017; 4: 248-252.

5. Kunin AA, Evdokimova AY, Moiseeva NS. Age-related differences of tooth enamel morphochemistry in health and dental caries. EPMA J 2015; 6: 3.

6. Ostrianko VI, Yakubova II, Tinkov VO. Study of composition of enamel of permanent teeth of method of X-ray Dispersive Spectral analysis. News of Stomatology 2015; 2: 82-88.

7. Abou Neel EA, Aljabo A, Strange A, et al. Demineralization-remineralization dynamics in teeth and bone. Int J Nanomedicine 2016; 11: 4743-4763.

8. Mamaladze M, Khutsishvili L, Zarkua E. Distribution of carious and non-carious cervical lesions and gingival recession at age related aspects. Georgian Med News 2016; 256-257: 18-23.

9. Peshkova EK, Pavlova TV. Morphofunctional aspects of the carious process. Modern High Technologies 2014; 2: 73-76.

10. Wada I, Shimada Y, Ikeda M, et al. Clinical assessment of non carious cervical lesion using swept-source optical coherence tomography. J Biophotonics 2015; 8: 846-854.

11. Chistyakova GG, Petrouk AA. Morphology of hard tissues of teeth with werdge-shaped defects. Modern Stomatology 2017; 4: 41-45.

12. Yoshizaki KT, Francisconi-Dos-Rios LF, Sobral MA, Aranha AC, Mendes FM, Scaramucci T. Clinical features and factors associated with non-carious cervical lesions and dentin hypersensitivity. J Oral Rehabil 2017; 44: 112-118.

13. Zabolotna II. Multilevel study of morphological substratum of dental enamel fractures. Actual Problems of the Modern Medicine: Bulletin of Ukrainian Medical Stomatological Academy 2011; 11: 78-81.

14. Yarova SP, Zabolotna II. Results of X-ray spectrum analysis of dental enamel fissures. Herald of Stomatology 2013; 2: 29-32.

15. Yarova SP, Zabolotna II. Features of prevalence and direction of enamel fissures of different groups of teeth. Herald of Stomatology 2012; 3: 60-64.

16. Zabolotna I. Investigation of the chemical composition of the enamel of patients with intact hard tissues and cervical pathology. Fundacja «Ośrodek Rozwoju Kompetencji Akademickich» Area nauki 2020; 1: 111-119.

17. Pavlova TV, Peshkova EK, Goncharov IYu, Kolesnikov DA, Nesterov AV. Impairments in the ultrastructure and macro- and microelement composition of hard tooth tissues in caries in patients with hypothyroidism and in those without thyroid disease. Arch Pathol 2014; 2: 17-21.
18. Michael JA, Kaidonis JA, Townsend GC. Non-carious cervical lesions: a scanning electron microscopic study. Aust Dent J 2010; 55 : 138-142.

19. Abdalla R, Mitchell RJ, Ren YF. Non-carious cervical lesions imaged by focus variation microscopy. J Dent 2017; 63: 14-20.

20. Walter C, Kress E, Götz H, Taylor K, Willershausen I, Zampelis A. The anatomy of non-carious cervical lesions. Clin Oral Investig 2014; 18: 139-146.

21. Faye B, Sarr M, Benoist FL, et al. Prevalence and etiologic factors of non carious cervical lesions among prison's population in Dakar. J Dent Oral Care Med 2015; 1: 1-6.

22. Asma Saher Ansari, Amynah Tariq Sheikh, Imtiaz Ahmed, Syed Jaffar Abbas Zaidi. Morphological analysis of cementoenamel junction types in premolars and molars of a sample of Pakistani population. J Ayub Med Coll Abbottabad 2019; 31: 221-225.

23. Femiano F, Femiano R, Femiano L, Festa VM, Rullo R, Perillo L. Noncarious cervical lesions: correlation between abfraction and wear facets in permanent dentition. Open Journal of Stomatology 2015; 5: 152-157.

24. Klimuszko E, Orywal K, Sierpinska T, Sidun J, Golebiewska M. Evaluation of calcium and magnesium contents in tooth enamel without any pathological changes: in vitro preliminary study. Odontology 2018; 106: 369-376.

25. Korshunov AP, Suntsov VG, Pitaeva AN, Toropov VN, Doronin VP. Physicochemical aspects of ion transport through dental enamel. Stomatologiya 2000; 4: 6-8. 